\title{
FILOSOFÍA Y NACIONALISMO EN CHILE LA TEORÍA DEL CHILENO DE ROBERTO ESCOBAR
}

\author{
$M g\left(\mathbb{C}\right.$ Alejandro Fielbaum S. $^{*}$
}

A partir de la consideración del vínculo entre la dictadura militar y la promoción del pensamiento nacionalista y de los usos del paisaje en la construcción de las narrativas nacionales, se indaga en la obra de Roberto Escobar. En particular, en su Teoría del Chileno (1981) y su defensa del rol del filósofo como poseedor del secreto de la nación, capaz de expresar la posibilidad de compatibilizar modernización e identidad.

Palabras clave: Roberto Escobar, fllosofia, nacionalismo, filosofia en Chile, identidad.

\section{PHILOSOPHY AND NATIONALISM IN CHILE THE THEORY OF THE CHILEAN OF ROBERTO ESCOBAR}

From the consideration of the link between military dictatorship and the promotion of nationalist thought, and the uses of landscape in the construction of national narratives, we read critically the work of Roberto Escobar. In particular, its Teoria del Chileno (1981) and its defense of the philosopher as the owner of the secret of the nation that can make compatible modernization and identity.

Keywords: Roberto Escolar, philosophy, nationalism, philosophy in Chile, identity.

* Universidad de Chile, Santiago,Chile. Correo electrónico: afielbaums@gmail.com 
"Creo que es un signo de madurez no preguntarse ya "qué es lo chileno". Las personas adultas no se preguntan quiénes son, sino cómo van a actuar"

$(\text { JORGE TEILLIER })^{1}$

Es Bastante COMÚN, EN vaRIados CAMPOS CULTURALES, LA ASOCIACIÓN entre la dictadura militar y la total ausencia de cultura. La famosa noción del "apagón cultural" da a entender, precisamente, que las distintas manifestaciones del arte o el saber solo pudieron subsistir marginal o clandestinamente, o bien que fueron totalmente prohibidas en tan sombríos años. Allí, se deja entrever, la cultura parecía imposible. Entre la luz de la cultura y la oscuridad de la barbarie no habría posibilidad de tránsito alguno. Ante esta consideración general, claro está, no queda más que concluir que, institucionalmente, no podría haber habido filosofía durante la dictadura. $\mathrm{Y}$, en tal gesto, asegurar la bondad de la propia institución, la que pareciera entonces incapaz de contaminarse con la violencia que sería su antítesis, y menos aún poder haberla apoyado. En tal sentido, Jaksic indica que el Golpe representó un duro Golpe a los filósofos chilenos ${ }^{2}$. Quien lo haya aceptado, se deja entrever, habría abandonado la filosofía, limitándose a repetir lo antes pensado sin originalidad alguna. Aún reconociendo la importancia de autores como Osvaldo Lira, la descripción de José Jara sobre la época permite considerar que en la nueva alianza de palabra y de obra entre la dictadura y un segmento de filósofos que describe no se habrían generado nuevas verdades. La verdadera filosofía, por el contrario, habría sufrido la prohibición de decir la verdad: "Las expresiones del pensar fueron drásticamente desplazadas desde las tonalidades de voces libres a los imponderables artificios de la sobrevivencia, equilibrándose entre el silencio, el temor y la palabra precisa"3.

Tal imagen subsiste incluso en los trabajos en los que se ha revisado minuciosa, incluso estadísticamente, la producción filosófica de la época descrita. En uno de ellos, Cristián Retamal refiere a los efectos dramáticos del Golpe en la filosofía, sin dejar de reconocer el de ciertas verdades por parte de la dictadura, pero sin avanzar en el necesario análisis de su suplementaria consideración de otras nuevas, ausente aún en los análisis sobre el

1 Telllier, Jorge, "Sobre el mundo donde verdaderamente habito o la experiencia poética", en Prosas, Sudamericana, Santiago, 1999.

2 Jaksic, Iván, "Chile", en Garcia, Carmen (Comp.), Pensamiento universitario latinoamericano. Pensadores y Forjadores de la Universidad Latinoamericana, Bid \& Co. Editor, Caracas, 2008, p. 258.

3 JARA, José, "Un siglo corto de filosofia", Archivos. Revista de Filosofia, No 1, 2009, p. 83. 
periodo. Por ejemplo, Cecilia Sánchez indica que las posiciones de quienes no fueron exonerados habrían oscilado, con escasas excepciones, entre la seguridad de quien no se arriesga o la adhesión, más firme, a las concepciones del gobierno a través del neotomismo, el neoliberalismo o el nacionalismo, a partir de una concepción de la tradición como repetición de lo idéntico ${ }^{4}$. De ahí que la misma intérprete analogue la filosofía en la época con un monumento. Es decir, con un saber tan intocable como ausente de la vitalidad necesaria para su creativo ejercicio: "Su enseñanza aparece así desprovista de toda ilusión, como un ideal "vacío", comparable a un rito demasiado repetido en el cual sólo restan los gestos mecánicos de la ceremonia"s. Evidentemente, se deja ahí entrever que la dictadura no habría tenido expresión en la filosofía, debiendo limitarse entonces a negar su verdadero ejercicio.

Una lectura más atenta, sin embargo, permite notar que hubo institucionalidad filosófica en la dictadura, que no se limitó a repetir las verdades de la escolástica, y que varios de sus miembros apoyaron activamente el orden que se impuso en el marco de ciertas políticas culturales impulsadas por la dictadura. Ya el 23 de septiembre de 1973 Osvaldo Lira llama a los cristianos a suscribir al nuevo gobierno, cuyo nuevo Departamento Cultural cuenta con la participación del filósofo Gonzalo Ibáñez en su primera actividad, en $1974^{6}$. Evidentemente, con estos datos no intentamos exagerar el posible peso que puede haber tenido la justificación filosófica en la política de la dictadura, sino simplemente indicar que algunos pensadores no dejaron de trazar, desde la vocación filosófica, ideas que lo apoyaron. En ellas, el ideario nacionalista fue un presupuesto fundamental, según describen Grínor Rojo y Bernardo Subercaseaux ${ }^{8}$. Este último discute explícitamente la noción de apagón cultural, indicando que las profundas restricciones autoritarias fueron acompañadas por discursos tales como el de un nacionalismo basado en la concepción telúrico-metafísica del ser chilena. Es desde esa preocupación que nos interesa leer, en particular, a un autor chileno, desde la consideración de que también su institucionalidad produjo ciertos discursos. En particular, según Salas y Devés, desde 1981 la dictadura habría comenzado a fortalecer institucionalmente a algunos filósofos ${ }^{9}$. Los ejemplos son

4 Sánchez, Cecilia, "Filosofia universitaria y política en Chile 1950-1973", Universum, N¹2, 1997, p. 219. Incluso entre pensadores cercanos a la dictadura puede hallarse también el diagnóstico de la supuesta desconexión entre filosofia y dictadura. Así, para Estrella, la filosofia chilena habría desconocido la compleja, vasta y radical transformación realizada por la dictadura, y su pujante reforma liberal, al seguir presa de sus ideologías. Habrían sido más bien otros intelectuales, fundamentalmente economistas, quienes se habrian atenido a sus hechos. Estrella, Jorge, "Filosofia en Chile", Filosofía en Chile, Ril, Santiago, 1999, p. 108.

5 SÁnchez, Cecilia, Una disciplina de la distancia. Institucionalización de los estudios filosóficos en Chile, CESOC, Santiago, 1992, p. 200.

6 JARA, Isabel, De Franco a Pinochet. El proyecto cultural franquista en Chile. 1936-1980, Universidad de Chile, Santiago, 2006, p. 264.

7 Roso, Grinor, "Campo cultural y neoliberalismo en Chile", V VAA, II Escuela Chile-Francia. Transformaciones del Espacio Público, Universidad de Chile, Santiago, 2008, p. 82.

8 Subercaseaux, Bernardo, Historia de las ideas y de la cultura en Chile, Volumen III, Universitaria, Santiago, p. 280.

9 Devés, Eduardo \& SAlas, Ricardo, "La filosofía en Chile (1973-1990)", en Devés, Eduardo \& Pinedo, Javier \& Sagredo, Rafael, (Comps.), El pensamiento chileno en el siglo XX, Fondo de Cultura Económica, México, 1999, p. 202. 
conocidos, y poco se ganaría denunciando lo que ya ellos explicitaron con orgullo. Baste con indicar que Widow describe el Golpe como un milagro de Dios a principios de la dictadura ${ }^{10}$, o que, sobre el final de ella, Vial Larraín indica que la expresión "gobierno militar" no debía tener el sentido peyorativo que le habría atribuido una supuesta leyenda maniquea fabricada sobre Chile ${ }^{\mathrm{l}}$.

Es claro que con estos datos no desconocemos las mermas que sufrió la filosofia en Chile durante aquellos años, capaz de ser graficada brutalmente con múltiples ejemplos de clausuras, despidos y exilios. Al contrario, precisamente por lo determinante que fue el Golpe en el precario campo de la filosofía en Chile que resulta necesario leer su producción de nuevos conocimientos, y ya no solo su censura de otros tantos ${ }^{12}$. El escaso rendimiento que tales filósofos tuvieron es síntoma de lo que intentaron sostener, pero no excusa para soslayar el análisis de nuevos discursos que no pudieron sino haber partido, en efecto, redefiniendo los diagnósticos y problemáticas de la institución. Partiendo, claro está, por el dato mismo de una institución y la necesidad de mantener sus límites bien puestos. Es decir, al margen de la política en general, y del marxismo en particular. Roberto Escobar, por ello, rescata la normalización filosófica que se habría ganado tras las supuestas intenciones de la Unidad Popular de transformarla en política que siguiera los dictados del marxismo soviético. A mediados de los setenta destaca que se habría retomado la actividad a través de los centenarios de Tomás de Aquino y de Kant, entre otras tantas actividades que habrían permitido mirar con optimismo el futuro intelectual de Chile ${ }^{13}$.

El optimismo de Escobar no parece casual, considerando que ya durante la Unidad Popular es uno de los coautores -junto a futuros personeros y adherentes a la dictadura, de la importancia de Jaime Guzmán, Pablo Baraona o Hermógenes Pérez de Arce- de uno de los libros emblemáticos de la derecha por aquellos años. Allí, Escobar sostiene que la sociedad y sus creadores, incluyendo los filosóficos, deben evolucionar paralelamente para alcanzar las verdades necesarias. A saber, las que vincularían la universalidad apátrida de la verdad con la particularidad cultural del pueblo, culminando así un progreso económico entendido humanamente ${ }^{i 4}$. La restitución de la normalidad filosófica, por ello, pareciera no bastar para alcanzar un saber filosófico capaz de dirigir el proyecto pinochetista. Para ello, a Escobar le parecía necesario trascender la lectara de los autores europeos que, según describirá hace pocos años, no nos definen ${ }^{15}$, dirigiendo la universalidad filosófica ha-

10 Widow, Juan Antonio, "Significado de un despertar", en VV.AA., Estampas de Chile. (De la población hispánica a la experiencia allendista), Speiro, Madrid, 1974, p. 85.

11 JAKSIC, Iván, "La vocación filosófica en Chile. Entrevistas a Juan Rivano, Humberto Giannini, Gastón Gómez Lasa y Juan de Dios Vial Larraín", Anales de la Universidad de Chile, Sexta Serie, Nº 3, 1996, p. 170.

12 Demás está decir que lo mismo podría decirse sobre otros tantos campos de la cultura, los que, con un gesto similar, suelen preferir seguir pensando, por ejemplo, que en la dictadura no hubo música en lugar de analizar la industria cultural allí montada.

13 Escobar, Roberto, La flosofia en Chile, UTE, Santiago, 1976.

14 EscoBar, Roberto, "La situación de la cultura"; en VV.AA., Visión crítica de Chile, Portada, Santiago, 1972, p. 252.

15 EscoBar, Roberto, Nosotros los americanos, Ril, Santiago, 2001, p. 104. 
cia la definición de lo chileno. Sus trabajos, en efecto, se instalan en la equívoca posición que liga la pretensión filosófica de universalidad y la pretensión política de nacionalidad. Es sabido que, en las narraciones tradicionales de la historia de la filosofía, tales pruritos parecen contradictorios. Así, que se suela llamar idealismo alemán a los autores ubicados en cierto tiempo y espacio pareciera ser algo accidental, ya que sus verdades trascenderían todo tiempo y espacio. Poco importaría de dónde hayan surgido sus discursos. En caso de ser verdaderamente filosóficos, se piensa de forma generalmente implícita, habrían de traspasar toda frontera.

El cuestionamiento de Jacques Derrida a las estrategias tradicionales de lectura de la historia de la filosofía no puede sino encarar tal vínculo, al considerar que la relación entre la filosofía y la nación no sería accidental. Por el contrario, se trazaría de un trazo que excedería la consideración de la nación dentro de alguna semántica filosófica, relativa a la necesidad de autorizar el discurso nacional más allá de uno u otro dato empírico y recurrir a una constitución conceptual. También existiría una relación más ínsita, capaz de alcanzar la distribución de los distintos temas y conceptos. Evidentemente, con ello el argelino no busca considerar el discurso filosófico como patrimonio de un lugar, como podría realizarlo una lectura nacionalista de su historia al pensar como alemana cierta determinación conceptual de la nación, o bien develando lo "alemán" que podría haber en una u otra obra en función de la supuesta esencia que allí se expresaría. Al contrario, se trataría de pensar cómo los discursos de la filosofía, en sus producciones y lecturas, contribuyen a construir una u otra noción del lugar en el que se lo inscribe. En ese sentido, podría pensarse que la filosofía llevaría la marca de su historicidad impresa en una producción condicionada por su tiempo y espacio, aun cuando no refiera a ella. Ni, mucho menos, que sea de, o para, un lugar. Pero existen casos en que si se lo ha intentado, vinculando origen y destino de la universalidad filosófica a la particularidad nacional en la que se autoriza, en un gesto que no sería externo a la historia de la filosofía: "El nacionalismo por excelencia no es pues ajeno a la filosofía, como un accidente que vendría a pervertir una destinación esencialmente universalista, cosmopolitista, esencialista de la filosofía. Se presenta siempre como una filosofía, más todavía, como la filosofía, en nombre de la filosofía y pretende a priori a un cierto universalismo esencialista - demuestra con eso que la filosofía, por una paradoja de estructura que dominará pues este seminario, está siempre de alguna manera en potencia o en falta, como quieran ustedes, de nacionalidad y nacionalismo"116.

En ese sentido, el nacionalismo filosófico no se expresaría en nombre de una particularidad, sino desde la teleología universal que se presentaría en la nación particular ahí pensada. Predeciblemente, es la filosofía alemana, de Fichte a Heidegger, la que sirve a Derrida para pensar aquel vínculo -al igual que a Esposito ${ }^{17}$, Kedourie $^{18}$, Lacoue-Labarthe ${ }^{19}$ o Ringer $^{20}$, en

16 DerRida, Jacques, "Nacionalidad y nacionalismo filosófico". Disponible en http://www.jacquesderrida.com.ar/ textos/nacionalismo.htm (Revisado el 15 de agosto de 2012).

17 Esposito, Roberto, Communitas. Origen y destino de la comunidad, Amorrortu, Buenos Aires, 2003, capítulo IV.

18 Kedourie, Elie, Nacionalismo, Centro de Estudios Constitucionales, Madrid, 1988. 
los otros pocos ejemplos de las escasas lecturas de la relación entre filosofía y nacionalismo. La ausencia de Estado parece haber gestado allí la necesidad de reafirmar, también en el plano de la filosofía, a la nación. Los germanos podrían haber carecido de Estado, pero nunca de filosofía, y sería este último dato el que garantizaría la fuerza de su nacionalidad. De acuerdo a Marchant, allí y en los otros países dominantes de la escena filosófica europea, se habría promovido políticamente cierta verdad filosófica ${ }^{21}$. Aquello explicaría, para el pensador chileno, que en tales países se haya desarrollado la filosofía, a diferencia del caso español y su extensión hacia las posteriores naciones latinoamericanas. En ellas, indica Marchant, es a través de la poesía que el pueblo piensa su singular habitar en la historia.

Ese dato le permite a Marchant tanto una notable lectura de la tradición poética chilena como una inquietante desconsideración del ensayo latinoamericano. Es este último, hasta mediados del siglo XX, el modo de escritura que recoge en Latinoamérica la preocupación por describir argumentativamente la colectividad, desde estrategias harto distintas a la determinación conceptual. Liliana Weinberg, cuya extensa reflexión harto ha aclarado acerca del desarrollo del ensayo en el continente, indica que allí no solo se imagina y disputa el territorio desde el que se habla, sino también la posición del letrado que escribe y su posibilidad de colaborar, desde su posesión del secreto de lo común, con su desarro$10^{22}$. Y es claro que aquello parte en lo relativo a la mirada desde la cual puede trazarse el saber que se requiere. En particular, una vez que comienzan a delimitarse espacios de enunciación académicos que se valen, en determinados casos, de estrategias ensayísticas que se intersectan con la particularidad de la propia disciplina. Así, desde mitades del siglo recién pasado, también los pruritos de algunas filosofías nacionales comienzan a disputar la nación. El caso mexicano parece haber sido el más productivo al respecto. Sin embargo, en otros países del continente, la cuestión de la nación no fue objeto exclusivo de discusión política o sociológica ${ }^{23}$. En tal sentido, resulta discutible la tesis, sostenida por Gabriel Castillo para la filosofía en Chile y Argentina, de que la filosofía se haya comprendido como relación abstracta con una cultura que condicionaría la inteligibilidad del sujeto que la piensa sin que éste se preguntase por su fundamento histórico y cultural ${ }^{24}$.

19 Lacoue-Labarthe, Philippe, La ficción de lo político, Arena, Madrid, 2002.

20. RINGER, Fritz, El origen de los mandarines alemanes: la comunidad académica alemana 1890-1933, Barcelona, Pomares-Corredor, 1995.

21 Marchant, Patricio, “"Atópicos”, “etc”, e “indios espirituales”", Escritura y temblor, Cuarto Propio, Santiago, 2000 , p. 382.

22 Weinberg, Liliana, "El ensayo latinoamericano entre la moral de la forma y la forma de la moral", Cuadernos del CILHA, $\mathrm{N}^{\circ} 9,2007$, p. 120.

23 No deja de ser sintomático del carácter continental que se impuso a la vocación localista de la filosofía el que sean escasos los textos que refieren a zonas determinadas, siendo mucho más abundante la bibliografia sobre la cultura latinoamericana en su generalidad, incluso cuando se busca rescatar una y otra parte de ella como la realmente vinculada. A modo de contraejemplos nacionales, además del texto de Escobar, podríamos nombrar a Astrada, Carlos, El mito gaucho, Cruz del Sur, Buenos Aires, 1948, y Ramos, Samuel, El perfil del hombre y la cultura en México, Espasa-Escalpe, Madrid, 1952.

24 Castillo, Gabriel, "Flujos de imaginario, sistemas de sentido y refracción del estilo en el Chile del primer tercio del siglo XX", Las estéticas nocturnas: ensayo republicano y representación cultural en Chile e Iberoamérica, Pontificia Universidad Católica, Santiago, 2003, p. 31. 
Por el contrario, precisamente el prurito de filosofías nacionales reside en la consideración de la historia y la cultura desde su fundamento. Es decir, desde el saber al que únicamente la filosofía podría acceder.

Durante la dictadura chilena, en efecto, la reconstrucción de la semántica de la nación debe pasar también por cierta institución filosófica que el Estado no deja de motivar a través de sus editoriales e instituciones. Sin ello, parece haber sido imposible la creación de un espacio desde el cual pensar la nación, contra las previas lecturas de la realidad nacional realizadas desde ciencias sociales fuertemente influenciadas por el marxismo. La dictadura, sin embargo, parece haberse centrado en un proyecto de modernización ante el cual incluso la filosofía adherente no puede sino partir discutiendo el subordinado rol que se le otorga. Osvaldo Lira es claro al respecto: "No es que no se sepa filosofía, por ejemplo. Es que no se sabe siquiera lo que es filosofia. De un lado, estas disciplinas no se cotizan. Del otro, en cambio, se denomina filosofía a cualquier posición o actitud que se adopte ante un determinado problema, aunque esa actitud no tenga la menor relación con las disciplinas filosóficas propiamente tales"25. Ante aquel contexto, el sacerdote propone la necesidad de devolver a las Humanidades la función que otrora tuvieron, y así restablecer los valores de Occidente que se hallarían amenazados tanto por la tecnocracia liberal como por el marxismo. La reconsideración del intelectual no solo sería importante, entonces, para retornar a la filosofía y sus verdades más allá de la contingencia. Antes bien, sería necesario el pensamiento sobre la libertad espiritual como puesta en acto de lo que debe resguardarse contra el eventual totalitarismo del ateísmo soviético. Sin el resguardo de la filosofía, no parece imposible la destrucción espiritual de la nación chilena. Los discursos tradicionalistas de la dictadura, en efecto, insisten en su necesidad contra la tecnocracia neoliberal que amenaza con la subsunción de todo saber al valor del mercado. Por ello, Barceló critica la poca importancia que se le daría a la filosofía, pese a la imperiosa necesidad de que exista en el país ${ }^{26}$. Sin la verdad, el ingreso del relativismo parece irreversible. $\mathrm{Y}$, con ello, la chance de la vuelta a la sofística marxista. Para conjurar definitivamente su abstracta moralidad, parece haber sido necesario recuperar el particular saber de lo chileno que resistiría a ello.

Sergio Jarpa, en efecto, indica que el marxismo habría alcanzado el poder cuando el organismo nacional ya se hallaba corroído por dolencias crónicas, tales como la pérdida del sentido de nacionalidad, la influencia preponderante de ideologias foráneas, el desarraigo espiritual de los chilenos, el olvido de la propia historia y el desconocimiento del medio geográfico ${ }^{27}$. El marxismo sería entonces un síntoma del cuerpo que se habría

25 LiRA, Osvaldo, Respuesta a la pregunta "¿Cómo se manifiesta la cultura occidental en la disciplina que Usted cultiva?", en Godoy, Hernán (Coord.), Chile en el ámbito de la cultura occidental, Andrés Bello, Santiago, 1987, p. 283.

26 BARCELó L., Joaquín, "La actividad filosófica en Chile en la segunda mitad del siglo XX", en AstorQuizA, Fernando (Editor), Bio-Bibliografia de la Filosofia en Chile desde el s. XVI hasta 1980, Barcelona, Chile, p. 112.

27 JARPA, Sergio Onofre, "Nacionalismo y política externa", en CAMPOS MenÉndez, Enrique (Comp.), Pensamiento nacionalista, Gabriela Mistral, Santiago, 1974, p. 316. 
enfermado por alejarse de su origen. Recién conociéndose a sí misma, la nación podría alejar definitivamente al cáncer marxista de su cuerpo, y sanarse afirmando su soberanía desde lazos tan estables como prologandos. Más honda que la de tribu, más durable que la de clase y más verdadera que la de raza, la idea de nación, indica Arturo Fontaine, permite pensar el nuevo modelo de desarrollo. Y, coherentemente con tal pretensión de mismidad, habría de generar sus propios conceptos para ello: "aprendan que sus juicios acerca de sí mismos y del país tienen que ser originarios de Chile y no copiados de los best-sellers sociológicos internacionales. Conciencia chilena es aprehensión de la individualidad de Chile, de la continuidad de nuestra historia y de la vocación de nuestro pueblo"28. Los conceptos que allí se dejan entrever son delimitados con más claridad por el ya mencionado Lira, quien describe a la nación como unidad de destino en lo universal. Su lectura del término también enfatiza en la necesidad de una nación de conocerse y determinarse conscientemente. Pareciera ser que el nuevo contexto brindaría una inédita posibilidad de pensar en ella, ante la vuelta del dato de la nación que se habría ausentado. Pues es ella, dice Lira, la que aflora después del Golpe de Estado ${ }^{29}$.

Es a partir de lo escrito por este último sacerdote, en torno a Vásquez de Mella, que Roberto Escobar abordará la explícita tarea de pensar la nación chilena en su curiosa Teoria del Chileno. Se trata de un libro casi desconocido, en contraste con los trabajos de Escobar sobra la historia de la filosofía en Chile. Difícilmente podría haberlo sido de otro modo, dada la escasez de libros sobre este último tema, afortunadamente mucho más vigente en la discusión filosófica que la cuestión de la chilenidad. Sin embargo, nos parece que las conservadoras posiciones que bien se han objetado a las narraciones de Escobar sobre la filosofía chilena ${ }^{30}$ pueden comprenderse a partir de la concepción de lo chileno que puede hallarse en el libro que nos interesa. $\mathrm{Y}$, con ello, brindar la chance para repensar, más allá de Escobar, lo que pueda entenderse por Chile como tiempo y espacio de la filosofía cuando referimos a las historias de la filosofía en el país. El texto de Escobar ofrece una chance interesante al respecto, al intentar pensar filosóficamente a Chile como culminación de un pensamiento que desde allí se realiza. Su lectura no ha sido realizada, a excepción de las breves y lúcidas indicaciones de Francisco Pinedo acerca del lugar de Escobar en el ensayo impresionista tradicional en el marco del conservadurismo opuesto a las reformas neoliberales ${ }^{31}$. Es decir, junto a otros tantos intelectuales que parecen haber replicado, en el campo de las ideas, la propuesta basada en un nacionalismo corporativista

28 Fontaine, Arturo, "Ideas nacionalistas chilenas", en Campos Menéndez, Enrique (Comp.), Pensamiento nacionalista, Gabriela Mistral, Santiago, 1974, p. 244.

29 Lira, Osvaldo, "Nación y nacionalismo", en Campos MenĖndez, Enrique (Comp.), Pensamiento nacionalista, Gabriela MistraI, Santiago, 1974, p. 22.

30 JAKSIC, Iván, Academic rebels in Chile. The Role of Philosophy in Higher Education andPolitics, State University of New York Press, Albany, 1989, p. 161; Santos, José, "200 años: Apuntes para una historia episódica de la filosofia en Chile”, Mapocho, N67, 2010, pp. 323-352; RuIz, Carlos, “Roberto Escobar, El vuelo de los búhos: Actividad filosófica en Chile de 1810 a 2010" (Reseña), Revista de Filosofia, V, 65, Santiago, 2009, pp. 226-229.

31 Pinedo, Francisco, "Cinco momentos claves en el ensayo chileno contemporáneo", Actas del X Congreso de la Asociación Internacional de Hispanistas, Vol. 3, 1992, p. 898; cfr. "Conservadores chilenos y su oposición a las reformas neoliberales de Pinochet”, Estudios interdisciplinarios de América y el Caribe, Vol. 13 (1), 2010. 
antes que neoliberal, retomando, con un nivel de abstracción mayor que exige todo lo que se precie de ser filosófico, la discusión que bien ha cartografiado Verónica Valdivia a propósito de las discusiones internas en el Ejército durante aquellas décadas ${ }^{32}$. Uno de tales intelectuales, en efecto, es el ya mencionado Lira, cuya obra aparece como una de las tantas "Ilustraciones" del libro. Con ese nombre, Escobar denomina a injertos de otros textos que aparecen al final del libro. La de Lira recuerda que la nación posee un alma propia. Es decir, un principio vital y espiritual que le da cohesión y unidad ${ }^{33}$. Escobar se vale de ello para abordar su análisis sin discutir el concepto de nación, dando por supuesta aquella unidad que buscará pensar a partir de sus concretas manifestaciones. Por ello, tal ilustración va acompañada que refieren a anécdotas antes que a discusiones teóricas, para luego dar paso a una referencia selectiva a obras sobre lo chileno en las que se nombra, por ejemplo, a Papelucho, los textos de Encina o Keyserling, las meditaciones orteguianas sobre el pueblo joven o al Neruda de Arte de pájaros y Piedras en el cielo, sin mención alguna, por ejemplo, al Canto General -ni hablar, claro está, de lo pensado por Faletto, Ramírez Necochea o cualquier otro pensador de izquierda.

No es necesario, sin embargo, llegar a esta sección final del libro para sorprenderse. Basta con abrir el índice y notar los sobresalientes nombres de las secciones del texto: Chile-Logia o Estudio de Chile, Chile-Grafía o Descripción de lo chileno y Chile-Tesis o Teorías de lo chileno. Comparecen, en ellas, dudosos argumentos filosóficos con la descripción del viaje en tren, una receta de chancho en piedra o sus cálculos acerca de la composición étnica del mestizo chileno. En ella, por ejemplo, los judíos habrían aportado con un $10 \%$, transmitiendo así una cultura descrita con burdos niveles de esencialismo: "Su idiosincrasia es mesiánica, teocrática, patriarcal, guerrera, amantes de las artes y la música, habituados a resistir adversidades. Muy religiosos y unidos entre sí"34. Los mapuches, por su parte, habrían aportado otro décimo del total. Junto al $2 \%$ relativo a los africanos, compondrían el $12 \%$ de la posición mítico-natural que mantendría la chilenidad a través de supersticiones que se ocultarían como piedad cristiana, por lo que su origen se desconocería ${ }^{35}$. El filósofo, por cierto, habría de exceder aquel saber antropológico para comprender el legítimo sentido de tales prácticas. Escobar concibe su figura, en efecto, como la de un amante de los mitos. Solo a través de ellos, deja entrever décadas más adelante, podría dar con lo que debiera pensar. A saber, la verdad la relativa al tiempo y espacio donde vive. Así, considera quien se pregunte filosóficamente sería quien indague quiénes somos, dónde estamos y cómo vivimos ${ }^{36}$. Contra toda reducción culturalista de su trabajo, habría de alcanzar, desde tales datos, la dimensión conceptual. De hecho, parte de su tarea sería interpretar aquello en sus categorías de Tiempo y Espacio y en la explicación existencial de su $\mathrm{Ser}^{37}$.

32 Valdivia, Verónica, Golpe después del Golpe: Leigh v/s Pinochet. Chile 1960-1980, Lom, Santiago, 2003.

33 Escobar, Roberto, Teoria del chileno, Corporación de Estudios Contemporáneos, Santiago, 1981, p. 186.

34 Ibid, p. 75

35 Ibid, p. 79

36 Escobar, Roberto, Nosotros los americanos, Ril, Santiago, 2001, p. 12.

37 Idem., p. 58. 
A partir de tan curioso acercamiento, Escobar aborda la pregunta por lo chileno. La particular cifra de su pueblo residiría, para el autor, en la forma intemporal en que la vida se viviría. No está de más indicar que Escobar replica tal postura al analizar, años después, la cultura latinoamericana mediante instrumentos de análisis igualmente curiosos, tales como un Mapa Escobar de la Cultura Americana en el que denomina al Caribe como América dispersa ${ }^{38}$ o un cálculo similar al ya descrito sobre el peso de las tradiciones culturales en el año 2000 que concluye, por ejemplo, que los neoafricanos influirian en un $11,3 \%$ con características que parecieran oponerse, tajantemente, a la racionalidad occidental: "El sentido artístico de los africanos y su actitud sensual y afectuosa hacia la vida marcan en forma innegable la vida iberoamericana"39. Ese dato sería uno de los tantos que permite pensar su distancia ante la lógica occidental del espacio y el tiempo. Desde sus obras más tempranas, en efecto, Escobar distingue la progresión temporal del mundo europeo con la ausencia de linealidad existente en Latinoamérica. En lugar de un legado temporal, sería el espacio el que se impondría ante el hombre latinoamericano. Y es que este viviría en una geografía abrumadora, difícil de ser habitada por el hombre ${ }^{40}$. Ninguna cultura pareciera poder imponerse sobre su naturaleza, al punto que pareciera imposible cualquier planificación exitosa sobre su inmensidad. Por ello, a diferencia del peso de la tradición propio del hombre europeo, su estabilidad sería puramente territorial ${ }^{41}$. La experiencia del hombre americano jamás podría de atender a lo que lo excede. Antes que a través de la ciencia que se abstrae del mundo, indica Escobar, sería en el arte, por su capacidad de refiejarlo, donde el hombre americano se expresaría mejor ética y estéticamente. Ya en la Colonia, señala, puede destacarse que los americanos pintaban como Murillo sin haber visto jamás un cuadro europeo ${ }^{42}$. El hombre americano se desplegaría, entonces, en un espacio sin tiempo. Así, Escobar retoma el tradicional tópico del exceso de la geografía que se deja leer ya desde las primeras crónicas coloniales, y que no deja de prolongarse, con torsiones varias, hasta el siglo XX. El ya mencionado Teillier, quien llegó a conclusiones harto distintas desde la primacía de otra consideración de la tierra, indica lúcidamente que el peso de la tierra es tan decisivo, en Chile, como el bullado peso de la noche ${ }^{43}$.

Al menos, lo dicho parece certero para la ensayística chilena, como bien lo demostró Cecilia Sánchez ${ }^{44}$, del siglo en que escribe Escobar. Lo particular del análisis de este último es que piensa de una soledad americana capaz de subsumirse en la nación que la

38 Idem., pp. 60-61.

39 Idem., p. 76.

40 Escobar, Roberto, “La utopía como constante filosófica en América”, Revista de Filosofia, Vol. XVI, N 1-2, 1978, p. 35.

41 Escobar, Roberto, Músicos sin pasado. Composición y compositores en Chile, Pomaire, Santiago, 1971, p. 52.

42 "Dardos contra Europa" (entrevista a Roberto Escobar), en Artes y Letras, 13 de enero del 2002, p. 12.

43 Teillier, Jorge, "Los poetas de los lares. Nueva visión de la realidad en la poesía chilena", en Prosas, Sudamericana, Santiago, 1999, p. 22.

44 SÁnchez, Cecilia, "A la espera del milagro. Naturaleza, soledad, mesticidad e intrahistoria en el mundo social latinoamericano", en Ossandón, Carlos (Comp.), Ensayismo y modernidad en América Latina, Arcis-Lom, Santiago, 1996. 
acoja, precisamente por ser constituida por hombres que saben vivir ante la inmensidad que rodea al hombre americano. Es decir, la soledad como dato desde el cual se forja, $y$ confirma, la nación que trasciende a sus solitarios hombres. Bien indica Gorelik a partir de la ensayística argentina, que esta tendió a ver, en la inmensidad y dispersión de geografía, la ausencia de la nación ${ }^{45}$. En el caso de los autores estudiados por Sánchez, podría alcanzarse una conclusión similar. Escobar, por el contrario, da allí con el dato nacional, retomando la larga tradición de la retórica de la excepcionalidad del paisaje chileno como dato de su distinta cultura. Rafael Sagredo ha descrito, en efecto, su progresiva valoración de la geografía en el Chile postcolonial, en contraposición a las descripciones españolas del inhóspito territorio chileno ${ }^{46}$. Si la imaginación colonialista atribuyó a esa diferencia la condición de un país inhóspito, la emergente construcción de la imaginación nacional revirtió tal valoración para hallar allí la posibilidad de un orden mejor. Tal como bien se ha descrito para el caso argentino, allí se instala una dimensión irreductiblemente geográfica en la construcción de una simbología patriótica ${ }^{47}$.

Ya en uno de los textos fundacionales de la imaginación de la soberanía nacional, Camilo Henríquez es claro en lo relativo a la diferenciación que la naturaleza impone a Chile con respecto a otras naciones: "encerrada como dentro de un muro y separada de los demás pueblos por una cadena de montes altísimos, cubiertos de eterna nieve, por un dilatado desierto y por el mar Pacífico'48. Huelga decir que, en el proyecto independentista de Henríquez, el aislamiento no impedía una concepción continental de la liberación. Parte de esta última, por el contrario, habría implicado la trascendencia ética de los límites naturales. Sin embargo, las posteriores derivas de la nación transformaron la particularidad geográfica en la materialidad a partir de la cual concebir una historia distinta del continente. Las narraciones sobre el país no solo indican la excepcionalidad política a través de la temprana consecución del orden político posibilitado por el autoritarismo portaliano ${ }^{49}$, sino también de su distinta geografía con respecto al resto del continente ${ }^{50}$. Como bien han destacado Cid $^{51}$ y Purcell ${ }^{52}$, fueron múltiples los agentes culturales que colaboraron con aquella construcción. Así, la conocida tesis de Góngora de la invención estatal de la nación ${ }^{53}$, requière ser

45 Gorelik, Adrián, "La imaginación territorial en el ensayo de 'interpretación nacional': de Ezequiel Martínez Estrada a Bernardo Canal Feijoó", Prismas, N 5, 2001, p. 311.

"46 SAGREDO, Rafael, “Chile, del orden natural al autoritarismo republicano", Revista de Geografia Norte Grande, $2006, \mathrm{~N}^{\circ} 36$, pp. 5-30.

47 Escolar, Marcelo \& Quinteros, Silvina \& Reboratti, Carlos, "Geographical identity and patriotic representation in Argentina”, en Hooson, David (Editor), Geography and national identity, Blackwell, Massachusetts, 1994, p. 348.

48 Henriquez, Camilo, "Proclama de Quirino Lemáchez", en Antologia, Universitaria, Santiago, 1970 , p. 63.

49 Collier, Simon, Chile: La construcción de una república 1830-1865, Universidad Católica de Chile, Santiago, 2005, pp. 197-206.

50 Cid, Gabriel \& Vergara, Jacinta, "Representando 'La copia feliz del Edén'. Rugendas: Paisaje e identidad en Chile, siglo XIX", Revista de Historia Social y de las Mentalidades, Vol. 15, N ², 2011, p. 122.

51 CiD, Gabriel, "La nación bajo examen", Polis, 32, 2012, p. 4.

52 Purcell, "Fernando, Fotografía y territorio en el imaginario nacional. Chile: 1850-1990", en Stuven, Ana María \& Pamplona, Marco (Eds.) Estado y nación en Chile y Brasil en el siglo XIX, Universidad Católica de Chile, Santiago, 2009.

53 Góngora, Mario, Ensayo histórico sobre la noción de Estado en Chile en los siglos XIX y XX, Universitaria, Santiago, 2003, pp. 71-73. 
matizada al analizar la emergencia de variados imaginarios por parte de artistas y literatos. Allí, la figura del paisaje parece haber sido central, lo que parece haberse prolongado más allá del siglo XIX.

No está de más insertar aquí un breve rodeo en torno a la figura del paisaje como una construcción social de particular rendimiento naturalizante. Ya Borges, tempranamente, cuestiona su imagen como la falsa disposición de una imagen prevista, de fácil emoción para quien resulta incapaz de una experiencia estética de mayor profundidad: "Ir a admirar adrede el paisaje es paralelizarnos con los salvajes de la cultura, con esos indios blancos que desfilan en piaras militarizadas por los museos y se quedan con los ojos arrodillados ante cualquier lienzo garantido por una firma sólida, y no saben muy bien si están ebrios de admiración o si esa misma voluntad de entusiasmo les ha inhibido la facultad de admirarse" 54 . Sin desconocer el racismo presupuesto en la escena descrita, resulta interesante la lucidez borgiana para notar la analogía entre museo y paisaje, en tanto erección de cierta imagen predispuesta de la naturaleza que aspira a que esta no se modifique. Lo cual, evidentemente, obedece a intereses humanos que no podrían excusarse como naturales. Lezama Lima, quien harto sabía de la producción del exceso natural como artificio, es claro al describir el paisaje como un diálogo entre hombre y naturaleza en el que la última se reduce a la altura del primero. Si hay paisaje en América, dice el cubano, es porque, irreductiblemente, hay cultura ${ }^{55}$. El ejercicio que resalta la naturaleza no podría sino demostrar, por su mirada, que se ha construido una forma histórica de mirar. Como bien indica Simmel, el paisaje no resulta una realidad natural, sino una forma específica de sentirla y describirla que surge históricamente: "La naturaleza, que en su ser y sentido profundo nada sabe de individualidad, es reconstruida por la mirada del hombre que divide y que conforma lo dividido en unidades aisladas en la correspondiente individualidad "paisaje»" a partir de las construcciones, y disputas, por el paisaje y sus límites. Según Isabel Jara, sería común el recurso nacionalista a esa forma de representación para imaginar la unidad nacional. En particular, claro está, cuando las discusiones sobre la nación resultan prohibidas. Si bien el imaginario cultural conservador habría apostado desde mucho antes a cierto refugio en la estética del paisaje como defensa de un supuesto mundo tradicional que la Reforma Agraria habría alterado, sería en la dictadura cuando el paisaje rebasaría su marco cultural para adentrarse en la enunciación política, apelando al reservorio simbólico tradicional para reelaborar las narraciones de la nación ${ }^{57}$. Según parece, habría operado allí cierta nacionalización de la naturaleza. Es decir, siguiendo la lúcida descripción de Kaufmann y Zimmer, una ubicación de los mitos, memorias y virtudes atribuidos a la nación en un paisaje particular que así se adosaría a la singularidad cultural de la nación.

54 Borges, Jorge Luis, "Crítica del paisaje", Textos recobrados (1919-1929), Emecé, Buenos Aires, 2001 , p. 101.

55 Lezama Lima, José, La expresión americana, Universitaria, Santiago, 1969, p. 111.

56 Simmel, Georg, "Filosofia del paisaje", El individuo y la libertad, Península, Barcelona, 1986, p. 176.

57 JARA, Isabel, "Politizar el paisaje, ilustrar la patria: nacionalismo, dictadura chilena y proyecto editorial", Aisthesis, No 50,2011 , p. 237. 
La chance contrapuesta descrita por los autores, en la analogía nacionalista entre paisaje y nación, es la de la naturalización de la nación. Es decir, la construcción de un determinismo geográfico que imaginaría paisajes particulares como expresiones espirituales de una nación que allí recibiría su forma ${ }^{58}$.

La apuesta de Escobar pareciera situarse en esta última opción, al partir de un vínculo nacionalista entre paisaje y nación que trata de pensar, desde la filosofía, mucho más profundamente. Es decir, como cierto don de la tierra a la cultura que no se agotaría en folklore alguno. Antes bien, Escobar retoma la consideración colonial de la hostilidad del paisaje chileno para pensar que su tipo particular de hombre no solo se explica por un mestizaje más homogéneo que en el resto del continente, sino también por una geografía mucho menos amable en su exceso, al punto que pareciera generar un desequilibrio entre las tres dimensiones que Escobar describe como constitutivas de cada situación cultural: El temperamento nacional, las personas y el lugar, entendiendo lo último como el paisa$\mathrm{je}^{59}$. Contra lo que podría suponerse, Escobar no caería en un determinismo geográfico absoluto, ya que la naturaleza podría vivirse de distintas formas, en función del temperamento. El punto es que la singular naturaleza chilena pareciera determinar su cultura, impidiendo una posible interacción mesurada, entre naturaleza y cultura, en la construcción del carácter chileno. Al contrario, este último destacaría por la incapacidad de imponerse ante la naturaleza que otros pueblos sí habrían logrado dominar: "Si bien el mar es siempre el mismo, en Chile se le mira siempre desde la tierra, mientras el europeo, mucho más navegante que el hombre de nuestras tierras, lo mira como parte de su quehacer, para el chileno el mar es "una voz" y no un lugar de estadía"60.

El dictado de la naturaleza generaría una percepción geográfica fragmentada, ante la incapacidad de abarcar todo de la singular mirada que debe detenerse en un presente cuyo peso impide la racionalización del tiempo y el espacio. Pareciera ser, entonces, que resulta aquí imposible, respectivamente, la planificación o la perspectiva. Por el contrario, las distintas manifestaciones culturales de lo chileno permitirían leer un curioso orden basado en la yuxtaposición antes que en la sucesión. Aquello explicaría incluso la falta de ritmo que padecería el fútbol en Chile ${ }^{61}$. Sin embargo, sería erróneo leer esta noticia como pura carencia. Por el contrario, entre tales dificultades, se lograría uno que otro éxito: "Los cerros son demasiado grandes para que valga la pena gritar; los pueblos sin montañas son más gritones. La actitud reflexiva proviene de la distancia psicológica que separa a cada individuo y de la necesidad de concentración aprendida del contacto con la naturaleza. Se camina agachado para ver el camino; así se han encontrado muchas minas"62. El desafío del paisaje habría así generado el sustrato del singular carácter del chileno, al que Escobar

58 KAUFMANN, Eric \& Zimmer, Oliver, "In search of the authentic nation: landscape and national identity in Canada and Switzerland", Nations and Nationalism, 4 (4), 1998.

59 Escobar, Roberto, Creadores musicales chilenos, Ril, Santiago, 1995, p. 82.

60 Ibid, p. 89.

61 EscoBar, Roberto, Teoria del chileno, Corporación de Estudios Contemporáneos, Santiago, 1981, p. 37.

62 Idem., p. 64. 
denomina sub-sole. Es decir, la fuerza telúrica del alma del chileno ante la adversidad material, cuya infinitud resultaría necesaria para perdurar en una existencia carente de la progresión temporal que permitiese ir superando tales dificultades. Por ello, sería a través del tesón individual que el chileno se sobrepondría. De ahí que el dato esencial del subsoleano sea el ñeque, el que ya se habría expresado en la Guerra de Arauco o la toma del Morro $^{63}$, y subsistiría en figuras como el maestro rural, el minero o incluso el escritor que escribe aunque no leerá64 ${ }^{4}$ Se trataría, entonces, de sujetos que se esforzarían al máximo sin la retribución que les sería justa. Tan curiosa economía habría generado, además del temperamento necesario para vivir en la adversidad, los principios que lo fundamentarían: "Nada es igual, todo es posible, la vida está en la veta, el ñeque lo puede todo"65.

En tal sentido, la particular vida del chileno desarrollaría, por así decirlo, su propia metafísica, cifrada en la potencia del paisaje que lo circunda. Décadas más adelante Escobar dice, en efecto, que resulta difícil no ser panteísta ante él ${ }^{6 \dot{6}}$. Sin embargo, tanto o más imponente podría ser el desvío de la mirada propio de quien se desconoce su origen. Pese a no poder superar la naturaleza, el chileno podría imitar a quienes sí lo hacen. $Y$ es que tendería al disfraz, lo que rápidamente lo haría denegar su esencia para transformarse en el antagonista del hombre sub-soleano: El superficie. Como deja entrever el vocablo escogido, se trataría de quien carece de profundidad. Ni siquiera alcanzaría, indica Escobar, a ser un estilo. Antes bien, se trataría de un conjunto ecléctico de prácticas y figura, sin consistencia ni dirección, que habría ingresado en el siglo XIX y se prolongaría en la adición de nuevas modas. El mestizaje que habría generado la patria, entonces, se habría mantenido puro, gracias a la supuesta afinidad entre el feudalismo español y la organización prehispánica que habría permitido generar la determinada unidad originaria del sub-soleano a la que se contrapondría la superficialidad de la imitación. Mientras la del sub-soleano sería una yuxtaposición coherente con su origen estable, la del superficie no alcanzaría, jamás, la realidad que el lugar le impone. A partir de esta binariedad entre quien se mantiene vinculado a su origen y el hombre desenraizado que copia del extranjero, Escobar lee ciertas tensiones tradicionales, tales como entre el campo y la ciudad, o entre el minero y el comerciante, ligando predeciblemente las primeras al origen y las segundas a la imitación. Y también, más sorprendentemente, cuestiones tales como los hábitos culinarios de las mujeres, contraponiendo a la tradicional mujer que trabaja la cacerola con la emergente, y progresivamente hegemónica, mujer "abre-latas": "Tal vez la mujer "abre-latas" se sienta "moderna", "eficaz" y "diligente"; no es ninguna de esas cosas, es solo una refugiada de la aculturación, una apátrida culinaria" ${ }^{67}$.

63 Una de las cuestiones políticas más interesantes en el discurso de Escobar, en efecto, reside en su consideración de la unidad nacional. A diferencia de los europeos, indica, los paises latinoamericanos habrían variado escasamente sus límites. Aquello le permite considerar, entonces, que lo chileno, forjado antes del siglo XIX, se expresaría en el acto en el que sus límites positivos se expanden. Como si, por asi decirlo, el destino de Chile hubiese sido su actual configuración geográfica.

64 Idem., 160.

65 Idem., p. 158.

66 Escobar, Roberto, El vuelo de los búhos. Actividad filosófica en Chile de 1810 a 2010, Ril, Santiago, 2008 , p. 474.

67 Escobar, Roberto, Teoría del chileno, Corporación de Estudios Contemporáneos, Santiago, 1981, p. 95. 
Lo problemático para Escobar es que, dado que el hombre superficie podría imitarlo todo, estaría también comenzando a aparentar ser sub-soleano. La preponderancia que tan problemático tipo de sujeto habría ido ganando después de la Segunda Guerra Mundial exigiría la máxima alerta. El espectador impávido podría confundirlos ante su creciente tendencia a disfrazarse incluso de chileno. Ese sería el caso del huaso, invención urbana de quien aspira a disfrazarse de la vida rural que ha perdido. Coherentemente con su falsa de coherencia, el hombre imitador creería que la originalidad se jugaría en la superficie y no en su fuerza. Así, imitaría lo tradicional en lugar de vivirlo: "Los hombres de ciudad que estudian falsos instrumentos musicales bajo el pretexto de que son andinos, dan una prueba clara de esto, ¿es que no hay trompetas y clarinetes, musicalmente mejores que esas tristes cañas? ¿Es que lo chileno no merece una música más vigorosa y viril?" ${ }^{68}$. En esa línea, lo importante no sería la forma en la que la música se toca, sino lo que expresa. Si la música comercial resulta problemática por su carácter totalmente internacional, no lo sería tanto porque hasta sus pelucas se repetirían de país y el país, sino porque no dependería, como la música artística, de su época y lugar ${ }^{69}$. Improvisada en un parrón por un campesino o planificada por una orquesta en una salón, podría expresar o no el alma chilena en la medida en que retome su origen. Sin tal gesto, difícilmente podría alcanzar algo de calidad: "Claro está que sólo existen dos clases de música: la BUENA y la MALA. $Y$ desde la perspectiva de crear una tradición musical que sirva para identificarnos como chilenos, lo que nos interesa es centrar la atención en la música BUENA, creada por chilenos y que aporte a una "imagen musical de Chile"” 70 .

La tensión contemporánea entre el falso y el verdadero original sería, entonces, la de quien consume la raíz y la de quien vive apegado a ella. No bastaría con desplazarse al campo para ser sub-soleano. Aquel error padecerían, por ejemplo, los turistas y estudiantes de Arquitectura que acuden los fines de semana a Pomaire. Estos últimos aspirarían a reformar su espacio de acuerdo a criterios urbanísticos que nada comprenderían al Pomaire real que retornaría tras el ajetreo del fin de semana, con su tiempo calmo y saber tradicional: "El lunes se apagan los amplificadores electrónicos de los restaurantes, y hasta el viernes canta el agua en las acequias, los pájaros dejan oír sus querellas; don Camilo vigila sus maíces y sus zapallos, refunfuñando solo; Cucho Caro saca las cuentas de sus tomates y medita sobre détente internacional, mientras en bicicleta a sus quehaceres; la señora Inés

Las apelaciones de Escobar a la cocina, en efecto, son recurrentes. El dato gastronómico no sólo parece interesante por asociarse a cierta escena tradicional y cotidiana, sino también por el vínculo entre naturaleza y cultura que alli parece resguardarse. Partiendo, claro está, por quien cocina y cómo se la resguarda. Escobar es claro al respecto: "La comida seguirá siendo nuestra mientras la cocinen nuestras mujeres" (Idem., p. 233). La cuestión del género, evidentemente problemática en distintos pasajes de la obra, acá parece particularmente evidente, ya que la modernización de los hábitos culinarios parece incluso afectar al cuerpo tradicional de la mujer chilena, y su necesidad de adelgazar ante la nueva arquitectura moderna. Asi, recuerda que su padre decía, irónicamente, que se necesitaban cocineras tan flacas que pudieran caminar de lado. "El 'Pudor' de la Arquitectura Chilena". (Entrevista con Roberto Escobar), 1981. Disponible en el catálogo virtual de Biblioteca Nacional de Chile.

68 EscoBar, Roberto, Teoría del chileno, p. 43.

69 Escobar, Roberto, Creadores musicales chilenos, Ril, Santiago, 1995, p. 57.

70 Ibid, p. 7 
inclinada sobre su máquina de coser, vigila la casa que le construyó don Lucho. A ciertas horas, Julieta Vera sale de su casa sin ventanas, con la vista en la eternidad y con ágiles pasos va al almacén en busca de algo"71. Se trata, evidentemente, de una imaginación tradicional de lo chileno, desde lo que refiere al reparto de roles de género hasta las actividades de los sujetos, pasando por su ausencia de tecnología medianamente modernizada, la ruralidad de sus gestos, el paisaje descrito o incluso los nombres y apodos de los sujetos. Parecen ser sub-soleanos puros, así como quienes aspirarían a modernizar su modo de vida serían superficies puros. Sin embargo, indica Escobar, la mayoría de los chilenos oscilarían entre uno y otro tipo, resguardando entre sus conductas imitativas algo de la verdad telúrica y atemporal de sus raices subsoleanas. En aquella indeterminación reside tanto la chance de la pérdida de la chilenidad como de su recuperación, siendo necesaria una toma de posición activa para que esta última sea la opción que prevalezca. De ahí la importancia de que el Estado promueva tal reconocimiento, a través de distintas políticas culturales. Evidentemente, Escobar no comprende aquello como la dirección estatal de la cultura. Esa habría sido la opción de la Unidad Popular, la que habría intentado instalar un estilo de vida foráneo que quebrase la singular idiosincrasia nacional en sus distintos niveles: "No hace mucho, en Chile soportamos el impacto de medidas culturales impuestas sin respeto a la libertad: la canción protesta, la pintura y la poesía al servicio de la política marxista, la violencia y el odio como sistema. El impacto de la angustia y la sensación de desamparo la sufrimos todos, y también pudimos observar cómo se deseaba destruir nuestro lenguaje y nuestra comida, para que así pudiéramos aceptar otra cultura, con otro estilo y otra ideología"72.

Contra esta lógica, el Estado debiera impulsar medidas que promoviesen la nacionalidad en merma, a través de distintas instituciones en las que puedan desenvolverse libremente los valores que el marxismo habría puesto en jaque. Por ejemplo, a través de Facultades de Arte donde ya no solo se aprenda a copiar, sino también a comprender la atemporalidad y fragmentación de la visión del chileno, y crear obras que lo reflejen. En una Academia así, dice Escobar, habría de discutirse su libro ${ }^{73}$. Por ello, este contrastaría con los hábitos imperantes de la filosofía chilena, la que pensaría un hombre distinto al de su país. Sin embargo, en los datos sobre las influencias del extranjero podría notarse la incomodidad del chileno con cualquier filosofía europea. Así, contrasta la escasa recepción de Kant y Hegel con la de Ortega, cuyas Meditaciones del Quijote calzarían con el individualismo exacerbado y atemporal del chileno $0^{74}$. Sin embargo, seguiría imperando una imagen de la filosofía propia del hombre de superficie. Así describe, de hecho, a quienes aspiran a ser un Descartes o un Kant chileno. Sin originalidad, tales hombres dejarian de buscar y trabajar la veta ${ }^{75}$. El buen filósofo, entonces, insistiría con tesón de sub-soleano

71 Escobar, Roberto, Teoria del chileno, p. 117.

72 Idem., p. 222.

73 Idem., p. 167.

74 Escobar, Roberto, "Visiones de Ortega desde Chile", Politica, No 30, p. 377.

75 Escobar, Roberto, Teoria del chileno, p. 26. 
en la comprensión del hermético carácter de lo propio, en lugar de imitar las formas ajenas de construir el saber. Confirmando sus verdades con la nación que allí se descubre, la filosofía podría alcanzar un saber que ya se inscribiría en el movimiento de la universalidad descrita para el caso alemán, sino para reafirmar la particularidad de cierto colectivo cuya carencia de tradición filosófica parece tornar imposible una posible apelación al género humano en nombre de su particularidad. Así, su verdad no generaría una ganancia para la humanidad que confirmaría, sino para la nación que se resaltaría. Desde aquel movimiento, la construcción de una filosofía desde Chile, sobre Chile, habría de colaborar con Chile, en un gesto que harto trascendería la institución filosófica. Ya en el siglo XIX, describe Escobar por aquellos años, la fuerte vida intelectual habría sido un factor decisivo para el triunfo en la Guerra del Pacífico. Y no tanto porque a través de la forja de la voluntad, lo que parece requerir de instituciones pedagógicos, sería posible superar el instinto y aceptar la muerte por fines patrióticos ${ }^{76}$. Sino también porque el propio saber colaboraría con las distintas esferas del arte de gobernar. Más allá de aquella gesta en particular, toda sociedad se enriquecería al desarrollar el saber, incluyendo el relativo a la filosofía: "Un sistema social que reconoce y valora las actividades intelectuales, incluyendo en ellas la educación, la ciencia y la filosofía, se encuentra mejor preparado para atender a las exigencias del progreso y para desarrollar un sistema eficaz de seguridad nacional’"77.

Así, un saber filosófico atingente a la particularidad del carácter nacional podría comandar una modernización que ya no se contraponga a la identidad chilena, sino que surja de esta y exponga, con su creatividad, los necesarios caminos por venir. Un año después del Golpe, en efecto, Escobar escribe un documento para el ministro y las Universidades en el que defiende la necesidad de la creación cultural, a partir del presupuesto de que ciencia y tecnología sólo podrían desarrollarse, superar la copia, desde el estímulo que el arte da a la creatividad: "Los artistas son los futurólogos de la sociedad; conviene utilizar sus visiones como una integración del quehacer científico y tecnológico"78. Es evidente que los futurólogos de la dictadura fueron otros. No parece casual, por ello, que la Teoría del Chileno finalice con la apelación a recuperar el humanismo que habría existido antes de la Segunda Guerra Mundial, tras la cual los intelectuales chilenos se habrían dedicado a imitar a los europeos. Contra este último hábito, habría una rica veta intelectual en el sub-soleano por rescatar, otorgando así la posibilidad a la Filosofía de pensar, en el nuevo orden, la particularidad histórica del pueblo por gobernar desde lo que su tesón brinda. De hecho, Escobar cuestiona la tradicional distinción entre la izquierda utópica y la derecha práctica -quizás apelando, implícitamente, a la derecha teórica que habría de representar su obra. Si la primera se entregaría al superficialismo soviético, la segunda caería ante la imitación del neoliberalismo. Autorizando la posición del intelectual en el nuevo orden, Escobar culmina su libro clamando por una filosofía que pueda pensar

76 Escobar, Roberto, "Eros y Thanatos", Revista de Filosofia, Vol. XXVII-XXVIII, 1986, p. 154.

77 Escobar, Roberto, "Vida intelectual de Chile en 1879", Atenea, N 447, 1983, p. 111.

78 Escobar, Roberto, "El arte en la Universidad chilena. Situación y perspectiva", p. 2. Documento disponible en la Biblioteca Nacional de Chile. 
la nación para resistir a ambas tendencias, y así colaborar con la reconstrucción de una nación que se reencontraría consigo misma: "La tarea para nuestra vida intelectual es la de retomar nuestro lugar en el continente, rehacer nuestra base humanista y científica, revisando prácticamente los alcances de la vida profesional y dar así una adecuación contemporánea al espíritu sub-soleano que caracteriza lo chileno. Es fácil dejarse llevar por la pendiente insensible que conduce al nuevo capitalismo, al materialismo extranjero y a la cultura inhumana del poder monetario y de la usura. Ello significa conducir al país al desarraigo de su idiosincrasia y a la pérdida de sus ideas propias. Chile puede elegir otro destino, retomar lo que le compete por razones históricas, naturales y culturales, pero esta vez sintetizar en una misma dirección su voluntad de ser y su aspiración al orden, configurando una expresión propiamente nuestra frente a la colectividad que ya es un hecho en esta época. Es decir, siempre nacer de nuevo, siempre volver a levantar lo derrumbado"79.

Tras ello, en mayúsculas, Escobar escribe el adagio latino post tenebras lux. Tal oración fue inscrita en el primer escudo chileno que se creó durante los primeros años de quiebre con el orden monárquico ${ }^{80}$. Pareciera así que, contra la posterior distinción entre la razón y la fuerza que sigue apareciendo en el emblema actual, Escobar aspirase a un orden basado la fuerza de la razón propia que podría emerger tras la hegemonía de la razón ajena que habría llevado al desorden. Allí es donde se situaría la importancia de la filosofía en el presente, así como la de conocer su pasado para nutrirse de lo que otros pensadores subsoleanos ya realizaron. Casi dos décadas después de su curiosa obra, Escobar sigue fundamentando así su trabajo antes de fallecer. Nos referimos a su reciente obra sobre la historia de la filosofía en Chile, concebida como su semblanza personal de los más destacados pensadores chilenos. Con ello busca, según dice, aportar al Bicentenario. Presentado por un general de la FACH que indica que las Fuerzas Armadas necesitan de la abstracción filosófica y que aspira a que su trabajo contribuya a la Nación que se es y a la que se puede llegar a ser ${ }^{81}$, el libro retoma los tópicos del sub-soleano o la geografía, con declaraciones igualmente insólitas. Ya en el inicio marca un posicionamiento curioso en torno a su relación con la historia que narra: "En este libro no hablo de mí mismo, porque ese no es mi propósito. Cuando he estado involucrado en algún acto de los descritos, me nombro por mi nombre. Así puedo mantener mi independencia para describir a los Búhos" "22. De más está decir que se trata de un presupuesto complicado. A saber, el de que la escritura en tercera persona asegura la neutralidad. En particular, si se sigue leyendo el libro para notar, rápidamente, que se caracteriza por problemáticas descripciones, inclusiones y exclusiones. Así, a modo de ejemplo, indica que nada en la obra de Bilbao podría considerarse filosófico ${ }^{83}$, arguye que la cercanía de Rivano con el MIR lo habría hecho ser opositor a Allende para luego tener un tiempo de alzas y bajas tras el cual habría resuelto

79 EscoBar, Roberto, Teoría del chileno, p. 179.

80 Cfr. http://www.gob.cl/la-moneda/emblemas-patrios/. Revisado el 16 de agosto del 2012.

81 Ortega, Ricardo, "Presentación", en Escobar, Roberto, El vuelo de los búhos. Actividad filosófica en Chile de 1810 a 2010, p. 13.

82 EsCOBAR, Roberto, op. cit. p. 17.

83 Ibid, p. 73. 
partir a Suecia ${ }^{84}$, describe la participación de Vial Larraín durante la dictadura en la OEA y la Universidad de Chile como una carrera institucional en el campo general de la "cultur $a^{\text {"85 }}$, recuerda el cargo de ministro de Clodomiro Almeyda en el gobierno de Ibáñez del Campo sin mencionar que también lo fue con Allende y Aylwin ${ }^{86}$ o destaca a Millas como "político", sin mencionar su militancia o postura, al punto de explicar su merma productiva posterior al Golpe por su texto sobre Alicia en el pais de las maravillas como parte de una salida humorística a su carácter melancólico: “ ¿En esto estaba el Maestro Millas!, mientras llovia en Valdivia"87.

El lector que conozca un mínimo de la vida y obra de aquellos autores rápidamente puede notar que son descripciones, más que incompletas, falsas. Quien se autoriza como testigo personal de la época no puede haber desoído buena parte de lo omitido o distorsionado en las descripciones recién mencionadas. Su deseo pareciera ser el de ocultar todo vínculo de lo que desea rescatar como filosofía chilena con la dictadura, y el de destruir todo lazo entre los trabajos filosóficos y alguna posición de izquierda. Y es que, podría pensarse sobre esta última, el internacionalismo teórico o el particularismo político no se dejan incluir en la consideración de Escobar de lo chileno desde un nacionalismo teórico y un particularismo naturalista. Las cartografías de Escobar sobre la filosofía en Chile parecieran ser así de erróneas por su concepción de lo chileno, y de las formas en que la filosofía habría de expresarlo, de acuerdo a lo antes descrito. Los efectos de su curioso nacionalismo filosófico, por ello, pueden leerse en las lecturas que desde allí traza. De ahí que algunos nombres se ausenten. Por ejemplo, el de Patricio Marchant, quien sí es nombrado en el texto de Escobar filosofía en Chile escrito tres décadas atrás, en el cual se indicaba que Marchant padecía una desesperación intelectual ante la que no tenía claridad, siendo entonces un prisionero del lenguaje $\mathrm{e}^{88}$. Pareciera que esa es la única cárcel que Escobar reconoce, sin siquiera comprenderla, al pensarla como un problema artificioso que se contraponen a los naturales de la patria que Marchant no podría pensar. Todo ejercicio deconstructivo, por ello, parece confundirse en sus límites. Es por ello que también el trabajo de Cecilia Sánchez es cuestionado con curiosos argumentos: "Cae en una de las tentaciones contemporáneas: los "estudios de género". Creo que este Tema fue agotado por Platón (La República): las mujeres tienen iguales condiciones que los hombres para realizar las mismas tareas -dice salvo que los hombres pueden levantar cosas más pesadas. Comparto ese juicio, plenamente, y no veo que haya mucho más que discutir"89.

A diferencia de este último caso, Escobar considera que otros pensadores sí habrían gestado ideas originales. Los búhos, en efecto, se destacarían por haber dejado la fácil imitación, aportando con ideas para la construcción de un modelo de desarrollo social y

84 Ibid, p. 411.

85 Ibid, p. 234.

86 Ibid, p. 374.

87 lbid, p. 188.

88 EscoBar, Roberto, La filosofia en Chile, UTE, Santiago, 1976, p. 122.

89 Escobar, Roberto, El vuelo de los búhos. Actividad filosófica en Chile de 1810 a 2010, p. 391. 
moralmente más profundo. A diferencia de las hojas de la erudición europea que algunos relucirían, en su caso lo importante sería el tronco chileno y sus ramas ${ }^{90}$. La metáfora es clara, y no casualmente recurrente en la ensayística latinoamericana. En particular, en Martí. Pero mientras él busca allí pensar la inserción en el mundo desde el origen nuestroamericano91, para Escobar se trata de pensar desde y para Chile, cuestionando todo posible cosmopolitismo. Pareciera que el riesgo de la exposición es demasiado, incluso en la propia nación. Escobar recalca, en efecto, que la mayoría de sus búhos no hayan sido santiaguinos ${ }^{92}$. Mientras en la ciudad se repetirían verdades ajenas ante hechos imposibles, los pensadores profundos dirían la verdad propia, acerca de los necesarios hechos que faltarían para retomar el origen que debe rescatarse. A diferencia del búho de Minerva como narrador retrospectivo del presente, el de Chile pareciera ser quien dice la verdad de lo que, por el imperio de la falsedad, no se ha prolongado. $Y$ es que pareciera imposible que sus verdades acontezcan ante un país que seguiría denegando de la filosofía, pese a haber emergido junto a ella. Ya en el principio de su tradición, sin embargo, Camilo Henríquez habría indicado que los legisladores fueron los mayores filósofos, siendo necesarios para generar Constituciones. Ante ello, Escobar ironiza acerca de si la filosofía es o no necesaria para Chile ${ }^{93}$. No está de más recordar que la vinculación demiúrgica entre filosofía y derecho es cuestión central de El Contrato Social, tal como este libro lo era para Henríquez. Escobar, sin embargo, omite toda mención al pensador francés, en una estrategia recurrente en las lecturas conservadoras de la Independencia ${ }^{94}$. Con ello, no solo pareciera desear una fundación puramente nacional, sino además a alejar toda problematización acerca de la relación posible entre expresión filosófica y voluntad democrática.

El filósofo, para Escobar, no diría la chilenidad en función de sus mayorías, sino precisamente de la raíz que las mayorías irían perdiendo. Su trabajo sería el de resguardar un secreto que estas bien podrían desconocer. Se trataría, entonces, de una verdad contra las

90 Ibid, p. 38.

91 Marti, José, Obras Completas, Vol. 6, Consejo Nacional de Ciencias Sociales, La Habana, 1991, p. 18.

Notablemente lúcida resulta, por ello, la imagen de Vaz Ferreira de Latinoamérica como una rama de muchos troncos europeos, restando alli toda posible vinculación telúrica de la cultura, por amplio que fuese el suelo como en el caso martiano. Se trataría, por ello, de una cultura necesariamente artificiosa y múltiple. Y no solo por ser una imagen algo monstruosa, sino también porque es tal indeterminación la que permite un mayor crecimiento desde el cual generar nuevas formas que no restituirían una previa presencia, sino que no podrían sino inventar en la medida en que se nutren, productiva e irresponsablemente, de lo ajeno: "se nos hace un poco indirecta, un poco excesiva, un poco ambiciosa nuestra tentación de ir a absorber directamente de aquellas capas primitivas, los jugos que nutrieron el tronco. Nuestra tarea es demasiado grande, tanto más cuanto que somos ramas de muchos troncos -y aqui falla la comparación:- debemos tratar de ser ramas de muchos troncos, debenos absorber muchas culturas diferentes; y esto es lo que hace precisamente las ventajas de nuestra situación, lo que quizá haga nuestras ventajas sobre nuestras muchas culturas madres, cuando hayamos pasado decisivamente de civilizados a civilizadores". VAZ Ferreira, Carlos, "Idiomas muertos y enseñanza clásica", Obras Completas. Edición Homenaje de la Cámara de Representantes, Tomo XXI, Montevideo, 1963, p. 428.

92 Escobar, Roberto, op. cit., p. 33.

93 Ibid, p. 25.

94 He intentado revisar tal cuestión, que acá ni siquiera podría asomarse por temas de espacio, en el trabajo "Latinoamérica y la Ilustración: Invenciones de la tradición y la traducción", presentado en el Tercer Congreso Latinoamericano de Estudiantes de Filosofía. 
mayorías, propia de quien insiste con un tesón que estas podrían desconocer. En efecto, en su último libro Escobar describe también al Filósofo chileno como un sub-soleano. Suspendido en la nada, sin tiempo alguno, perseguiría su trabajo con singular perseverancia y fe en lo invisible ${ }^{95}$. En un espacio tan carente de tiempo que puede así desconocer la historia del país y los espacios de enunciación desde los cuales escribe, el filósofo sería chileno por su verdad y no por su diálogo o auditorio. Por pensar la experiencia de quien vive bajo el sol desde una profundidad incapaz de pensar quien lo padece, como lo hiciera quien gestó la figura del sub-sole. Enceguecido por una luz que lo conectaría con su raíz tan directamente como para eludir la barbarie que fundamenta, Escobar narra así un estrecho nacionalismo filosófico tan peligroso por sus figuras de nación como por la historia de las ideas que de allí deriva. Ante lo cual, claro está, no queda sino insistir en la posibilidad de imaginar un esfuerzo filosófico distinto al del ñeque, a saber, el otro esfuerzo más del cosmopolitismo $0^{96}$ que permita un pensar desde el lugar que ya no se deje delimitar, en tema y auditorio, por los límites de la comunidad que imagina creyendo ser un saber de o para cierto lugar. Sino que, por el contrario, no deje, infinitamente, de alterar tales narrativas de la nación en nombre de lo excede cualquiera de sus fabulaciones de lo concreto, precisamente por su capacidad, estrictamente cosmopolita, de indeterminar toda concreción de lo común: "Ni todos hablan nuestra lengua ni en todos está nuestra sangre. ¡No importa! A una patria le basta tener leyes justas, para hacerse amar; le basta para incorporarlos a ella ofrecerles una tierra vasta, y esta patria, como cualquiera otra, para ser noble ha de tener, como Cristo, abiertos sus brazos hacia todos los hombres de la tierra"97.*

\section{Bibliografía}

Astrada, Carlos, El mito gaucho, Cruz del Sur, Buenos Aires, 1948.

Astorquiza, Fernando (Ed.), Bio-Bibliografia de la Filosofia en Chile desde el s. XVI hasta 1980, Barcelona, Chile.

Ariztía, Tomás (Ed.), Produciendo lo social. Usos de las ciencias sociales en el Chile reciente, Universidad Diego Portales, Santiago, 2012.

Borges, JoRge Luis, Textos recobrados (1919-1929), Emecé, Buenos Aires, 2001.

Campos Menéndez, Enrique (Comp.), Pensamiento nacionalista, Santiago, Gabriela Mistral, 1974.

95 Ibid, p. 477.

96 Derrida, Jacques, "On cosmopolitanism”, On Cosmopolitanism and forgiveness, Routledge, New York, 2001.

97 Mistral, Gabriela, "El patriotismo de nuestra hora”, Chile, pais de contrastes, Biblioteca Fundamentos de la Construcción de Chile, Santiago, 2009, p. 27.

* Artículo recibido: 19 de octubre de 2012. Aceptado: 23 de noviembre de 2012. 
CASTILLO, GABRIEL, Las estéticas nocturnas: ensayo republicano y representación cultural en Chile e Iberoamérica, Pontificia Universidad Católica, Santiago, 2003.

CID, Gabriel, "La nación bajo examen”, Polis, № 32, 2012.

Cid, Gabriel \& Vergara, Jacinta, "Representando "La copia feliz del Edén". Rugendas: Paisaje e identidad en Chile, siglo XIX", Revista de Historia Social y de las Mentalidades, Vol. 15, No 2, 2011, pp. 109-135.

CollIER, SIMON, Chile: La construcción de una república 1830-1865, Universidad Católica de Chile, Santiago, 2005.

Cristi, Renato, El pensamiento político de Jaime Guzmán. Autoridad y Libertad, Lom, Santiago, 2000.

DerridA, JACQues, "Nacionalidad y nacionalismo filosófico". Disponible en http://www. jacquesderrida.com.ar/textos/nacionalismo.htm.

, On Cosmopolitanism and forgiveness, Routledge, Nueva York, 2001.

Devés, Eduardo \& Pinedo, Javier \& Sagredo, Rafael, (Comps.), El pensamiento chileno en el siglo XX, Fondo de Cultura Económica, México, 1999.

EsCobar, RoBerto, Creadores musicales chilenos, Ril, Santiago, 1995.

tras, 13 de enero de 2002, p. 12.

--.--, "El arte en la Universidad chilena. Situación y perspectiva”. Documento disponible en la Biblioteca Nacional de Chile.

, "El 'Pudor' de la Arquitectura Chilena". (Entrevista con Roberto Escobar), 1981. Disponible en el catálogo virtual de Biblioteca Nacional de Chile.

---------------, El vuelo de los búhos. Actividad filosófica en Chile de 1810 a 2010, Ril, Santiago, 2008.

,"Eros y thanatos", Revista de Filosofia, Vol. XXVII-XXVIII, 1986, pp. $151-164$.

$111-114$.

"Hombres e ideas contemporáneas", Revista de Sociología, N 4, pp. 
, La filosofia en Chile, UTE, Santiago, 1976.

, "La utopía como constante filosófica en América", Revista de Filosofia, Vol. XVI, No 1-2, 1978, pp. 33-44.

-------------, Músicos sin pasado. Composición y compositores en Chile, Pomaire, Santiago, 1971.

, Nosotros los americanos, Ril, Santiago, 2001.

, Teoria del chileno, Corporación de Estudios Contemporáneos, Santiago, 1981 .

"Vida intelectual de Chile en 1879", Atenea, N 447, 1983, pp. 111-128. ,"Visiones de Ortega desde Chile", Política, $\mathrm{N}^{\circ} 30$, pp. 376-380.

Esposito, Roberto, Communitas. Origen y destino de la comunidad, Amorrortu, Buenos Aires, 2003.

Estrella, Jorge, Filosofia en Chile, Ril, Santiago, 1999.

Garcia, Carmen (Comp.), Pensamiento universitario latinoamericano. Pensadores y Forjadores de la Universidad Latinoamericana, Bid \& Co. Editor, Caracas, 2008.

Godoy, HernÁN (Coord.), Chile en el ámbito de la cultura occidental, Andrés Bello, Santiago, 1987.

GóngORA, MaRIO, Ensayo histórico sobre la noción de Estado en Chile en los siglos XIX $y X X$, Universitaria, Santiago, 2003.

GORELIK, ADRIÁN, "La imaginación territorial en el ensayo de interpretación nacional: de Ezequiel Martínez Estrada a Bernardo Canal Feijoó”, Prismas, Nº 5, 2001, pp. 283-311.

Henriquez, Camilo, Antologia, Universitaria, Santiago, 1970, p. 63.

Hooson, DAviD (Ed.), Geography and national identity, Blackwell, Massachusetts, 1994.

JaKsic, Iván, Academis rebels in Chile. The Role of Philosophy in Higher Education and Politics, State University of New York Press, Albany, 1989.

-, "La vocación filosófica en Chile. Entrevistas a Juan Rivano, Humberto Giannini, Gastón Gómez Lasa y Juan de Dios Vial Larraín", Anales de la Universidad de 
Chile, Sexta Serie No 3, 1996, pp.115-171.

JARA; IsABEL, De Franco a Pinochet. El proyecto cultural franquista en Chile, 1936-1980, Universidad de Chile, Santiago, 2006.

--_--_---olitizar el paisaje, ilustrar la patria: nacionalismo, dictadura chilena y proyecto editorial", Aisthesis, № 50, 2011, pp. 230-252.

JARA, JosÉ, "Un siglo corto de filosofía", Archivos. Revista de Filosofia, No 1, 2009, pp. $75-88$.

KaufmanN, Eric \& Zimmer, Oliver, "In search of the authentic nation: landscape and national identity in Canada and Switzerland", Nations and Nationalism, 4(4), 1998, pp. 483-510.

Kedourie, Elie, Nacionalismo, Centro de Estudios Constitucionales, Madrid, 1988.

Lacoue-Labarthe, PhilipPe, La ficción de lo político, Arena, Madrid, 2002.

LeZAma Lima, José, La expresión americana, Universitaria, Santiago, 1969.

Marchant, Patricio, Escritura y temblor, Cuarto Propio, Santiago, 2000.

MarTí, José, Obras Completas, Vol. 6, Consejo Nacional de Ciencias Sociales, La Habana, 1991.

Mistral, Gabriela, Chile, pais de contrastes, Biblioteca Fundamentos de la Construcción de Chile, Santiago, 2009.

OsSAndón, Carlos (Comp.), Ensayismo y modernidad en América Latina, Arcis-Lom, Santiago, 1996.

Pinedo, Javier, "Cinco momentos claves en el ensayo chileno contemporáneo", Actas del X Congreso de la Asociación Internacional de Hispanistas, Vol. 3, 1992, pp. 893906

-----------------, "Conservadores chilenos y su oposición a las reformas neoliberales de Pinochet", Estudios interdisciplinarios de América y el Caribe, Vol. 13 (1), 2010.

Ramos, Samuel, El perfil del hombre y la cultura en México, Espasa-Escalpe, Madrid, 1952.

RINGER, FRITZ, El origen de los mandarines alemanes: la comunidad académica alemana 1890-1933, Pomares-Corredor, Barcelona, 1995. 
Ruiz, Carlos, Reseña "Roberto Escobar, El vuelo de los búhos: Actividad filosófica en Chile de 1810 a 2010", Revista de Filosofia, V, 65, 2009, Santiago, pp. 226-229.

SAGREDo, RafaEl, "Chile, del orden natural al autoritarismo republicano", Revista de Geografia Norte Grande, 2006, n 36, pp. 5-30.

SÁNChez, Cecilia, "Filosofía universitaria y política en Chile 1950-1973", Universum, N ${ }^{\circ}$ 12, 1997, pp. 201-220.

-, Una disciplina de la distancia. Institucionalización de los estudios filosóficos en Chile, CESOC, Santiago, 1992.

SANTos, José, "200 años: Apuntes para una historia episódica de la filosofía en Chile", Mapocho, $\mathrm{N}^{\circ} 67,2010$, pp. 323-352.

Simmel, Georg, El individuo y la libertad, Península, Barcelona, 1986.

Stuven, Ana María \& Pamplona, Marco (Eds.), Estado y nación en Chile y Brasil en el siglo $X L X$, Universidad Católica de Chile, Santiago, 2009.

Subercaseaux, Bernardo, Historia de las ideas y de la cultura en Chile, Vol. III, Universitaria, Santiago, 2012.

TeILlier, JoRGe, Prosas, Sudamericana, Santiago, 1999.

Valdivia, Verónica, Golpe después del Golpe: Leigh v/s Pinochet. Chile 1960-1980, Santiago, Lom, 2003.

Vaz Ferreira, Carlos, Obras Completas. Edición Homenaje de la Cámara de Representantes, Tomo XXI, Montevideo, 1963.

VV.AA., II Escuela Chile-Francia. Transformaciones del Espacio Público, Universidad de Chile, Santiago, 2008.

dista), Speiro, Madrid, 1974.

, Estampas de Chile. (De la población hispánica a la experiencia allen, Visión critica de Chile, Portada, Santiago, 1972.

WeINBERG, LILIANA, "El ensayo latinoamericano entre la moral de la forma y la forma de la moral", Cuadernos del CILHA, $\mathrm{N}^{\circ}$ 9, 2007, pp. 110-130. 